\title{
Abstract \\ Can Gail Model be used in prediction of Breast Cancer in Sri Lankan population? A preliminary report
}

\author{
Bandaranayake BMVC $^{1 *}$, Perera WAHA ${ }^{1}$, Tennakoon TMIS ${ }^{1}$ \\ ${ }^{1}$ Teaching Hospital, Kandy, Sri Lanka
}

\begin{abstract}
Background

The Gail model is one of the most widely used tool in assessing the risks of breast cancer. Also it values in both identifying the high risk groups and patient counselling. However the validity of its application in local set up has not been assessed.

\section{Method}

Demographic and relevant clinical data were collected from diagnosed early breast cancer (DBC) patients between 44 to 65 years presented to Breast Clinic, Teaching Hospital Kandy from January 2015 to June 2015. Data from breast screening negative(SN) group within the same age range was taken for comparison.

Patient's age, age at Menarche and first live childbirth, family history and findings of the previous biopsies if performed were included in the on-line available Gail risk assessment tool and the ethnicity was selected as Asian. Relative Risk(RR) of developing breast cancer within the next 5 years and at the age of 90 years was calculated for each patient.

Results

Mean age of the DBC patients $(n=28)$ was $52.2( \pm 7.73)$ years, while the SN group $(n=39)$ was $48.1( \pm 7.8)$ years. In DBC and SN groups average RR within next 5 years was 0.654 and 0.54 , and at the age of $90,4.42$ and 4.32 , respectively. Comparison of RR within next 5 years from the students t test showed statistical significance $(\mathrm{P}<0.05)$.

Conclusion

Though Gail model was applied effectively with significant results, larger sample population with similar age distribution will be of value. A large scale prospective study would confirm its applicability in Sri Lankans.
\end{abstract}

Key words: Gail Model; Relative Risk breast Cancer; Screening

Copyright: (C) 2015 Bandaranayake BMVC et al. This is an open access article distributed under the Creative Commons Attribution License, which permits unrestricted use, distribution, and reproduction in any medium, provided the original work is properly cited.

* Correspondence : vathsal_b@hotmail.com

Cite this abstract as: Bandaranayake BMVC, Perera WAHA, Tennakoon TMIS. Can Gail Model be used in prediction of Breast Cancer in Sri Lankan population? A preliminary report. Anuradhapura Medical Journal 2015;9 (2Supp):S18.

DOI: http://dx.doi.org/10.4038/amj.v9i2Supp.7567 


\section{Submit your next Manuscript to Anuradhapura Medical Journal}

Submit your manuscript at http://amj.sljol.info/ 